\title{
Uso innecesario de exámenes de imagen
}

\author{
José D. Arce V', Cristian García B', Karla Moënne B', Enrique Bosch $O^{1}$.
}

1. Comité de Ética. Sociedad Chilena de Radiología. Santiago, Chile.

La radiología y las técnicas de imagen han tenido un desarrollo tecnológico explosivo y son hoy día un pilar para el diagnóstico médico. Desgraciadamente se ha abusado de estos métodos dejando de lado la anamnesis y el examen clínico, lo que ha traído como consecuencia una grave afectación de la relación médico-paciente. Esto contribuye a la despersonalización y deshumanización del acto médico, aumenta los costos de salud, transforma la medicina en una actividad empresarial y se crean conflictos de intereses.

Los exámenes de imagen usados en el diagnóstico médico deben ser un complemento del examen clínico que persigue evaluar la anatomía, fisiología y fisiopatología de las eventuales patologías que puede presentar un paciente. En sentido estricto, cada examen de imagen debería responder preguntas que surgen después de una adecuada anamnesis y un acabado examen físico. Nunca debiera solicitarse un estudio de imagen si el resultado de éste no va a modificar la conducta terapéutica ni otorgar alguna información relevante para al paciente.

El incremento sostenido en el número de estudios de imagen puede responder a causas diversas, que incluyen el aumento en la expectativa de vida, los avances tecnológicos y su mayor disponibilidad, factores que inciden parcialmente en su uso innecesario e indiscriminado.

Los conflictos de intereses también están presentes en la práctica de la radiología de manera diversa. Por un lado, el médico que deriva al paciente para un determinado examen podría recibir un estímulo económico por parte de la institución prestadora y por otro lado el médico radiólogo podría considerar la indicación de cierto tipo de exámenes en relación al beneficio económico que estos representan para sus ingresos.

Se aprecia un uso indiscriminado de exámenes complejos como Resonancia Magnética, Tomografía Computarizada y Tomografía por Emisión de Positrones - Tomografía Computada (PET-CT). Destaca que en algunos centros, al momento actual en otros países, éstos podrían estar disponibles para cualquier persona sin intermediación de un profesional médico, como cualquier consumidor privado puede acudir a una tienda a comprar algún producto.

El tema de la radiación diagnóstica y sus eventuales riesgos para los pacientes es complejo y controversial, del que se ha escrito mucho y no es el objetivo discutirlo ahora, pero debemos considerar siempre que la radiación utilizada con fines diagnóstico puede eventualmente facilitar el desarrollo de un cáncer y en este sentido los niños son claramente más sensibles al daño que los adultos. Por lo tanto, desde el punto de vista médico y ético, debemos exponer lo menos posible a radiación a los pacientes, porque en caso contrario caeremos en una violación del principio de no maleficiencia. Si los exámenes se usan con criterio y solamente cuando están indicados, los beneficios para el paciente superarán largamente los riesgos.

Para este efecto se ha desarrollado el concepto ALARA (As Low as Reasonably Achievable), cuyo objetivo fundamental es despertar conciencia de los riesgos de la radiación y lograr disminuir al mínimo posible las dosis de radiación utilizadas con fines diagnósticos.

Ahora bien, ¿está el radiólogo obligado a hacer o autorizar todos los exámenes de imágenes que solicitan los clínicos, aun cuando éstos no estén indicados o puedan significar un riesgo o un gasto innecesario para el paciente? En la práctica diaria de la mayor parte de los hospitales esta pregunta es difícil de responder, porque el radiólogo muchas veces no es siquiera consultado antes de solicitar o realizar el examen y oponerse a su realización puede significar un conflicto con sus colegas. Desgraciadamente, muchas veces el médico clínico se siente dueño del paciente y considera al radiólogo como un simple técnico. Para evitar llegar a este conflicto, es fundamental una adecuada relación entre los clínicos y los radiólogos para lograr un trabajo en equipo, teniendo como objetivo final el bienestar del paciente y de esta manera hacer los exámenes estrictamente necesarios, con el menor riesgo posible para el paciente. Es nuestra responsabilidad como radiólogos, educar y sensibilizar 
a los médicos clínicos en este sentido.

El rol de la llamada "Medicina defensiva", donde la indicación de tratamientos, exámenes y procedimientos pueden perseguir el fin de proteger al médico de la crítica o de una eventual demanda, ha sido importante en el aumento del número de solicitudes de estudios de imágenes. Un ejemplo claro de esto es el uso de exámenes en la medicina de urgencia.

En nuestra práctica local, la ausencia de guías para clínicos que orienten a un adecuado uso de las imágenes debe tenerse en cuenta. En Latinoamérica sólo la Sociedad Argentina de Radiología dispone de guías en la red y en forma de manual. Aun cuando los clínicos puedan no adherir a ellas, consideramos responsabilidad de quienes manejamos imágenes, informar a los médicos referentes respecto a sus potenciales riesgos por uso inadecuado. El Colegio Americano de Radiología, ha desarrollado normas completas y actualizadas, que pueden servir de referencia.

\section{En resumen}

- El uso indiscriminado e innecesario de las técnicas de imagen está reñido con la ética y requeriría de algún tipo de regulación. Estrictamente, los estudios de imagen deberían ser usados sólo cuando están indicados y cuando su resultado puede contribuir directamente en el diagnóstico y manejo terapéutico del paciente.

- Los avances tecnológicos, la deshumanización de la medicina y la medicina con fines comerciales han afectado seriamente la relación médico-paciente y generan desconfianza en la población.

- Los conflictos de interés pueden generar uso innecesario de los estudios de imagen. En la práctica diaria esto involucra a médicos radiólogos, médicos clínicos, instituciones e industrias.

- Podemos infringir el principio de no dañar o de no maleficiencia al someter al paciente a un riesgo innecesario, en particular en los métodos que utilizan radiación.

- Como consecuencia del uso innecesario de los exámenes se encarecen los sistemas de salud y los costos para el paciente, afectando directamente el principio de justicia.

- La medicina defensiva es un tema complejo y puede ser un factor causal difícil de regular.

- Debemos promover la enseñanza de ética y profesionalismo en radiología entre nuestros pares y en los alumnos de pregrado y postgrado de nuestras Facultades de Medicina.

\section{Referencias}

1. Lysdahl KB, Hofmann BM. What causes increasing and unnecessary use of radiological investigations? a survey of radiologists' perceptions BMC Health Services Research 2009; 9: 155.

2. Bhargavan $\mathrm{M}$, Sunshine $\mathrm{JH}$. Utilization of radiology services in the United States: Levels and trends in modalities, regions, and populations. Radiology 2005; 234: 824-832.

3. Matin A, Bates DW, Sussman A, Ros P, Hanson R, Khorasani R. Inpatient radiology utilization: Trends over the past decade. AJR Am J Roentgenol 2006; 186: 7-11.

4. Iglehart JK. Health insurers and medical-imaging policy-a work in progress. N Engl J Med 2009; 360: 1030-1037.

5. Guía de recomendaciones para la correcta solicitud de pruebas de Diagnóstico por Imagen. Segunda Edición. Sociedad Argentina de Radiología. http://www.aac.org. ar/imagenes/guias/guia_solic_diag_x_imagenes.pdf. Consultado el 22-09-17.

6. Dowling S, Spooner $\mathrm{CH}$, Liang $\mathrm{Y}$, et al. Accuracy of Ottawa Ankle Rules to exclude fractures of the ankle and midfoot in children: A meta-analysis. Acad Emerg Med 2009; 16: 277-287.

Arce J, et al. Uso innecesario de examenes de imagen. Rev Chil Radiol 2017; 23(3): 140-141.

Correspondencia: José Arce V. / jarce@clinicasantamaria.cl 